\title{
Clinical features of patients with chronic non-specific neck pain per disability level: A novel observational study
}

Hector Beltran-Alacreu, PT, PhD',2,3

Ibai López-de-Uralde-Villanueva, PT, PhD 1,2,3,4

(iD) César Calvo-Lobo PT, PhD

Josué Fernández-Carnero, PT, PhD 2,3,4,6

Doy La Touche, PT, PhD 1,2,3,4

\begin{abstract}
1. Department of Physical Therapy, Superior Center for University Studies La Salle, Autonomous University, Autónoma University of Madrid, Spain. 2. Motion in Brains Research Group, Institute of Neuroscience and Movement Sciences (INCIMOV), Superior Center for University Studies La Salle, Autonomous University, Autónoma University of Madrid, Spain. 3. Institute of Neuroscience and Craniofacial Pain (INDCRAN), Madrid, Spain

4. Hospital La Paz Institute for Health Research, IdiPAZ, Madrid, Spain. 5. Nursing and Physical Therapy Department, Faculty of Health Sciences, Universidad de León, Ponferrada, León, Spain. 6. Department of Physical Therapy, Occupational Therapy, Rehabilitation and Physical Medicine, Universidad Rey Juan Carlos, Alcorcón, Madrid, Spain.
\end{abstract}

http://dx.doi.org/10.1590/1806-9282.64.08.700

BACKGROUND: To date, there are no cross-sectional studies considering the influence of disability level in patients with non-specific chronic neck pain. Therefore, the main aim of this study was to determine kinesiophobia, active cervical range of movement (CROM), and pressure pain threshold (PPT) differences between different disability levels (mild, moderate, and severe) in subjects with non-specific chronic neck pain and asymptomatic subjects.

METHODS: A descriptive cross-sectional study. Subjects were recruited from a primary health care center and an outpatient department hospital. A total sample of 128 subjects, 96 of them with nonspecific chronic neck pain and 32 asymptomatic, were recruited. The NDI was used to divide the subjects with chronic neck pain into 3 groups (mild, moderate, and severe disability). The main outcome measurement was the Tampa Scale of kinesiophobia (TSK-11). The secondary outcome measurements were the Visual Analogue Scale (VAS), PPT (trapezius and tibialis anterior), CROM (flexion, extension, rotation, and lateral inclination) and pain duration.

RESULTS: The ANOVA results revealed, in the comparisons between groups, statistically significant differences for the VAS between the mild-severe $(P<0.01)$ and moderate-severe groups $(P<0.01)$, but not between the mild-moderate groups $(P>0.05)$; for the TSK, differences were not statistically significant $(P>0.05)$.

CONCLUSION: Kinesiophobia may not be influenced by disability level in patients with chronic non-specific neck pain. Nevertheless, pain intensity and chronicity of patients with severe neck disability are increased with respect to mild and moderate disability index.

KEYWORDS: Neck pain. Chronic pain. Disability evaluation.

ABBreVIATIONS: Cervical range of movement (CROM); Neck disability index (NDI); Pressure pain threshold (PPT); Tampa Scale of Kinesiophobia (TSK-11); Visual Analogue Scale (VAS).

DATE OF SUBMISSION: 15-Dec-2017

DATE OF ACCEPTANCE: 24-Dec-2017

CORRESPONDING AUTHOR: César Calvo Lobo

Av. Astorga, s/n - Ponferrada - León - Spain - 24401 - Tel: 605811782

E-mail: cecalvo19@hotmail.com

CORRESPONDING AUTHOR: Josué Fernández Carnero

Department of Physical Therapy, Occupational Therapy, Rehabilitation and Physical Medicine.

Faculty of Health Sciences, Rey Juan Carlos University, Madrid, Spain.

Avda. Atenas s/n - 28922 Alcorcón - Madrid - Spain - Tel.: +34 914888949

Email: josuefernandezcarnero@gmail.com

hector.beltran@lasallecampus.es

ibai.uralde@gmail.com

josue.fernandez@urjc.es

roylatouche@lasallecampus.es 


\section{INTRODUCTION}

Neck pain is a very common condition in clinical practice. ${ }^{1-5}$ Recently, the International Neck Pain Task Force reported the impact of neck pain in social-related problems for families, work, health systems, and economies. ${ }^{1-3}$ The prevalence of neck pain ranges between $30 \%$ and $50 \%$ in the general population of developed countries ${ }^{3,4}$ and is more prevalent in women than men., ${ }^{1,5}$ In 2010, 33.6 million people were affected worldwide, and neck pain was the 4 th most frequent disability, with over 291 conditions studied..$^{5}$ The most common form of neck pain is non-specific chronic pain, which has a postural or mechanical basis and affects about two-thirds of people at some stage in their lives. ${ }^{6,7}$

Previous studies have shown an association between neck disability and chronic neck pain. ${ }^{8-10}$ In addition, physical factors, such as active range of movement (ROM), and psychological factors, such as fear of movement, anxiety, or depression, are also associated with chronic neck pain. ${ }^{8-10}$ To explain the relationship of neck pain with these factors, a "fear-avoidance model" may be used when the patient demonstrates avoidance-hypervigilance, which triggers a vicious cycle in which the patient is affected both physically and psychologically, leading to deconditioning. ${ }^{8,10-12}$ Fear of motion may be correlated with neck kinematics, such as ROM or velocity. Also, The neck disability level may be partly related to ROM. ${ }^{9}$ Furthermore, the pressure pain thresholds (PPT) of muscles, such as upper trapezius and tibialis anterior, have been widely used in order to evaluate local tenderness and central sensitization associated to chronic neck pain. ${ }^{13}$

Currently, no observational studies exist on non-specific chronic neck pain with different levels of disability, according to the neck disability index (NDI) ${ }^{14,15}$ the Neck Disability Index (NDI The NDI is a clinical screening tool established for pathology-related neck pain. ${ }^{16}$ The NDI has sufficient support in the literature and is the most commonly used self-report measure for neck pain. ${ }^{17}$ There is a lack of observational studies that make it more difficult to classify this type of patient, ${ }^{18}$ and classification could lead to a better therapeutic approach in the choice of treatment.

Therefore, the main aim of this study was to determine the kinesiophobia, active cervical range of movement (CROM), and PPT differences between different disability levels (mild, moderate, and severe) in subjects with non-specific chronic neck pain and asymptomatic subjects. Indeed, the pain intensity and chronicity influence were only established regarding NDI levels in patients with neck pain. As a secondary purpose, the association between these physical and psychological variables was analyzed in patients with non-specific chronic neck pain.

\section{METHODS}

Study design

A descriptive cross-sectional study was performed to assess differences in various physical and psychological outcomes of subjects with different levels of neck disability and asymptomatic subjects. The investigation was conducted according to the STROBE statement from November 2014 to November $2016,{ }^{19}$ which hampers the assessment of its strengths and weaknesses and of a study's generalisability. The Strengthening the Reporting of Observational Studies in Epidemiology (STROBE Before beginning the study, all participants were asked to read and sign an informed consent. Previously, the Ethics Committee for Clinical Research of the Hospital Universitario La Paz, Madrid, Spain (Registration number: PI-1241) approved the study.

\section{Setting, evaluators and blinding}

Subjects with chronic neck pain were recruited by referral from the primary health care center of Coslada (Madrid, Spain) and from an outpatient department of University Hospital La Paz (Madrid, Spain).

Two physiotherapists with over 5 years of experience in orthopedic manual therapy carried out the outcome measurement. A one-hour-long training session was scheduled to review how to perform measurement of the CROM and PPT protocols in the current study. In addition, they were responsible for collecting all outcome data without being aware of the subject's group, resulting in a single-blinded study.

\section{Sample}

A total sample of 128 subjects, 96 patients and 32 asymptomatic subjects, was recruited for the study. These subjects were classified by the NDI, ${ }^{20}$ obtaining a final sample of 96 patients, divided into 3 disability groups: 32 patients ( 25 females, 7 males; mean \pm SD age, $40.88 \pm 11.31$ ) with mild disability (MIL; NDI 5-14 scores), 32 patients (28 females, 4 males; $44 \pm$ 14.64) with moderate disability (MOD; NDI 15-24 scores) and 32 patients (27 females, 5 males; 42,66 \pm 
11.90) with severe disability (SEV; NDI 25-34 scores). The symptomatic subjects were selected upon fulfilling the following inclusion criteria: aged between 18 and 65 years; proper understanding, writing, and speaking ability of the Spanish language; experienced neck pain for at least 12 weeks and complained of pain localized in the neck region. Patients were not considered if they reported any of the following conditions: neck pain associated with whiplash injuries, a reported red flag medical history (tumor, fracture, metabolic diseases, rheumatoid arthritis, osteoporosis), neck pain with cervical radiculopathy, neck pain associated with externalized cervical disc herniation, fibromyalgia syndrome (checked by a physician against the criteria established by the American College of Rheumatology), ${ }^{21}$ previous neck surgery, neck pain accompanied by vertigo caused by vertebrobasilar insufficiency, or neck pain accompanied by non-cervicogenic headaches. People were also not considered if they were undergoing any type of pain treatment, or had received physical therapy in the previous 3 months. ${ }^{8,13}$

The control group consisted of 25 females and 7 males (mean \pm SD age, $43.38 \pm 10.67$ ) recruited from family, friends, and the same environment as the patients' primary health center. The approach for this group was to ask the relatives of the patients if they wanted to participate in the study. All subjects of this group presented an age range between 18-65 years and were excluded if they had a history of cervical, upper limb, orofacial, or upper thoracic pain in the previous 12 months.

\section{Outcome measurements}

The main outcome measurement was the Tampa Scale of kinesiophobia (TSK-11). The secondary outcome measurements were the Visual Analogue Scale (VAS), PPT (trapezius and tibialis anterior), CROM (flexion, extension, rotation, and lateral inclination) and pain duration (months). The TSK-11, PPT, and CROM were assessed in patients and asymptomatic subjects. Nevertheless, VAS and pain duration were only measured in patients with non-specific chronic neck pain.

\section{Self-report measures}

Neck Disability Index (NDI): The NDI is a well-validated 10-item questionnaire, with each item rated on a 0 to 5-point scale. The sum of the 10 items gives a score between 0-50. ${ }^{14}$ According to Vernon's NDI sub-classification, ${ }^{14,15}$ this scale divides the sample into 5 groups of disability: scores of $<4$ indicate no disability, 5-14 mild disability, 15-24 moderate disability, 25-34 severe disability, and $>35$ complete disability. In the current study, the complete disability group was not taken into account due to the lack of sample in clinical practice. The NDI has sufficient support in the literature as the most commonly used instrument for reporting neck pain; ${ }^{14,17}$ a Spanish validation of the index was used. ${ }^{20}$

Visual Analogue Scale (VAS): Pain intensity was measured via the VAS. A 100-mm horizontal line with pain descriptors marked "no pain" at the left side and "the worst pain imaginable" at the right side was used to measure pain intensity. Patients were asked to indicate their pain intensity at the time by marking the VAS with a perpendicular line. The VAS is a reliable and valid measurement of pain. ${ }^{22,23}$

Tampa Scale of Kinesiophobia (TSK): To evaluate the participants' pain-related fear of movement and (re)injury, a Spanish-validated Tampa Scale of Kinesiophobia (TSK) was used. ${ }^{24}$ a Spanish version of the TSK has not been available, up to now. Thus, the aim of this study was to validate the Spanish version of the TSK in 2 different pain samples: Alu00aOheterogeneous chronic pain sample $(\mathrm{n}=125$ We used an 11item version of it that has shown good psychometric reliability for chronic pain. ${ }^{25}$ Each item is scored on a 4-point Likert scale, ranging from "strongly agree" to "strongly disagree." Total scores range from 11 to 44, with higher scores indicating more fear of movement and/or (re)injury.

\section{Physical measures}

Cervical range of movement (CROM): Active ROMs of the cervical spine was evaluated using the CROM, which consists of 3 inclinometers attached to a lightweight plastic frame secured with fastening straps. The protocol used was a sequence of 3 measurements, with an interval of 30 seconds between each measurement. The CROM has shown good intra-rater reliability for subjects with and without neck pain (ICC $=0.87$ to 0.94 in asymptomatic subjects and ICC $=0.88$ to 0.96 in neck pain subjects). ${ }^{26}$ The following movements were measured by the CROM device (Figure 1): flexion and extension, right and left lateral flexion, and right and left rotation.

Pressure pain threshold (PPT): A digital algometer (FDX 25, Wagner Instruments, Greenwich, CT, USA), comprised of a rubber head $\left(1 \mathrm{~cm}^{2}\right)$ attached to a pres- 
sure gauge, was used to measure the PPT, which is defined as the amount of pressure at which the sense of pressure first changes to pain. ${ }^{27}$ fibrositis, myalgic spots, activity of arthritis as well as assessment of sensitivity to pain can be diagnosed by PTM. This study therefore established standards for pressure threshold as well as the reproducibility and validity of measurement in 24 male and 26 female normal volunteers at 9 sites. Muscles frequently afflicted by trigger points were examined. The deltoid was chosen as a reference since it is rarely a site for trigger points. Comparison of corresponding muscles on opposite sides failed to demonstrate significant differences (except for 1 muscle in females The force was measured in kilograms (kg); therefore, thresholds were expressed in $\mathrm{kg} / \mathrm{cm}^{2}$. The protocol used

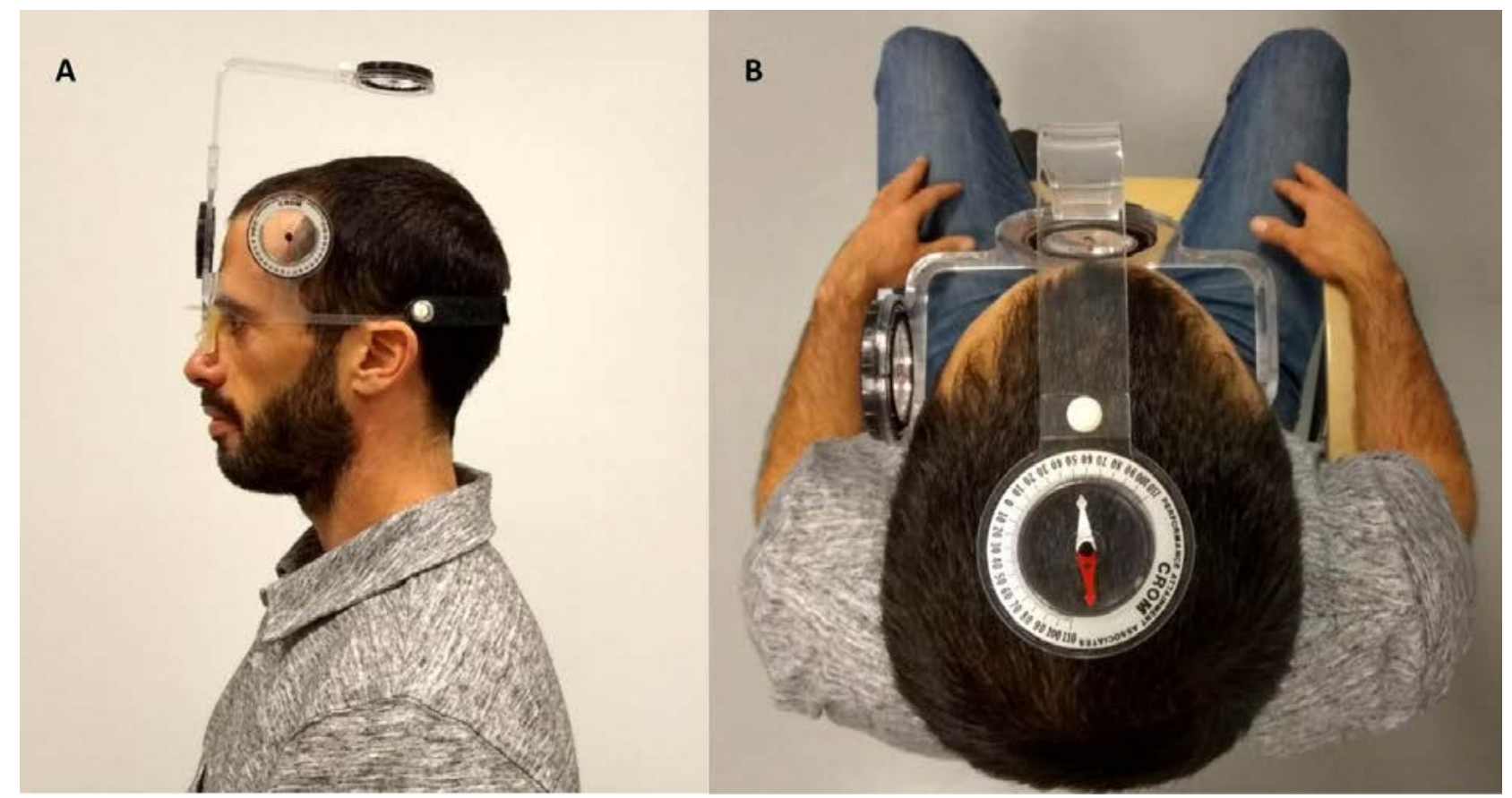

FIGURE 1. Lateral (A) and cranial (B) views for the CROM device use for active cervical movement measurement. Abbreviations: CROM, cervical range of movement.

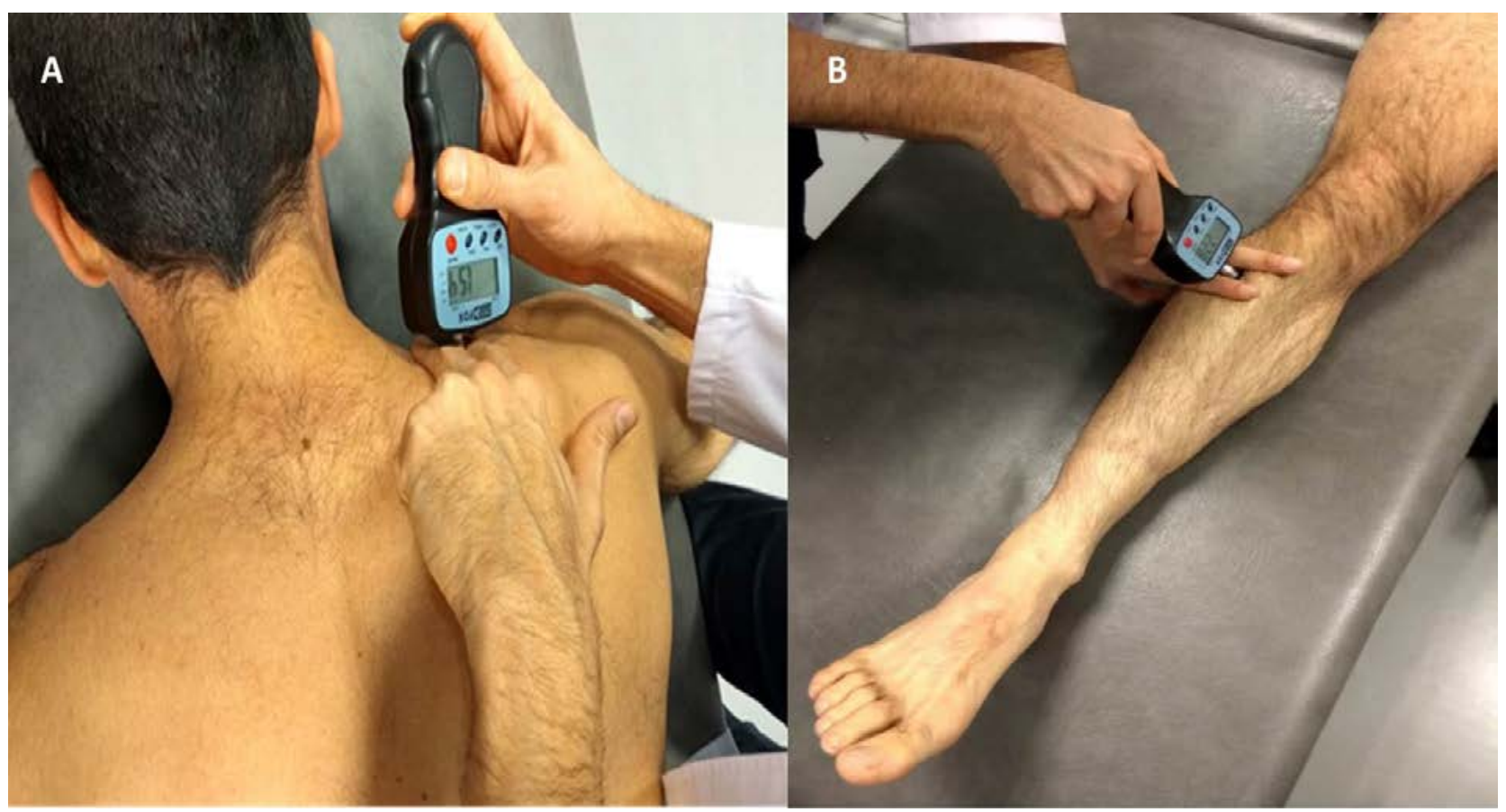

FIGURE 2. PPT assessment over the right upper trapezius muscle ( $A$ : midway between $C 7$ and acromion) and the right tibialis anterior muscle (B: upper one-third of the muscle belly). Abbreviations: PPT, pressure pain threshold. 
was a sequence of 3 measurements, with an interval of 30 seconds between each of them. The reliability of the pressure algometry was high $($ ICC $=0.91[95 \%$ confidence intervals (CI): 0.82-0.97]. ${ }^{28}$ At a rate of 5 Newtons (N) PPT was assessed over the right upper trapezius muscle (midway between $\mathrm{C} 7$ and acromion; Figure $2 \mathrm{~A}$ ) and the right tibialis anterior muscle (upper one-third of the belly muscle; Figure 2B). The upper trapezius muscle was chosen as the most common site of idiopathic neck pain, and the tibialis anterior was chosen as a remote distant site.

\section{Procedure}

The data collection was performed in a room in which only the assessor and patient were present. First, the measurement protocol was explained to the subject, then the informed consent was signed by the subject. Next, the questionnaires were filled out, and the patients' CROM and PTT measured, always in the same order. This study was conducted just before patients began treatment in their respective physiotherapy service. The asymptomatic subjects were healthy participants who accompanied the patients.

\section{Sample size calculation}

The sample size and power calculations were performed with appropriate software (G*Power 3.1). ${ }^{29}$ To obtain $95 \%$ statistical power (1- $\beta$ error probability) with an $\alpha$ error level probability of 0.05 , a one-way fixed-effects analysis of variance (ANOVA) model and

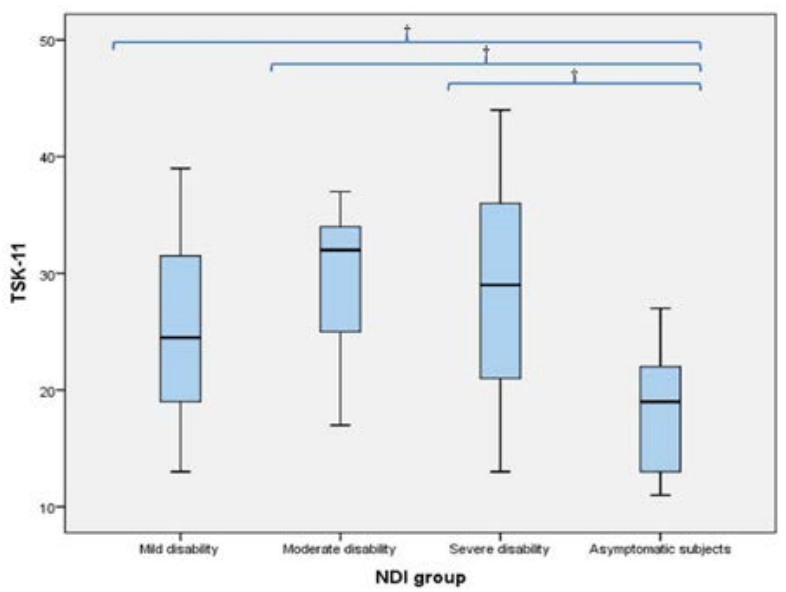

FIGURE 3. Box-plot to illustrate the TSK-11 differences between patients with different NDI level (mild, moderate and severe) and asymptomatic subjects. Abbreviations: NDI, neck disability index; TSK, Tampa Scale of Kinesiophobia. $† P$ $<0.01$ The rest of comparisons between groups did not show any statistically significant difference $(\boldsymbol{P}>0.05)$. a large effect-size of 0.4 were used, generated for 4 groups and a total sample size of at least 112 participants (28 participants per group).

\section{Statistical methods}

Data were analyzed using the Statistical Package for the Social Sciences (SPSS version 20.0; SPSS, Inc, Chicago, IL). Results are expressed as mean, standard deviation (SD), considering the 95\% CI. The Z-score was assumed for all variables to follow a normal distribution based on the central limit theorem, ${ }^{30,31}$ with 95\% confidence intervals, and compute cost-effectiveness acceptability curves and confidence ellipses. Two alternative non-parametric methods for estimating INB are to apply the central limit theorem (CLT Differences in demographic and clinical features between all groups were compared using ANOVA for continuous data and the $X^{2}$ test of independence for categorical data. Quantitative data (i.e., VAS TSK-11, pain duration, CROM, and PPT) were analyzed with parametric tests. One-way ANOVA with post hoc Bonferroni correction was used to analyze the outcome differences. TSK-11, PPT and CROM were compared between patients with different NDI level (MIL, MOD and SEV) and asymptomatic subjects. However, VAS and pain duration were only analyzed between these disability levels in patients with non-specific chronic neck pain. Pearson's correlations were calculated separately for MIL, MOD and SEV groups and were also calculated for subjects with NDI scores between 5-34 (total sample with disability). The values of $r$ for moderate or high correlation were considered between 0.50-0.70 and 0.70-0.90, respectively. ${ }^{32}$ For all analyses, statistical significance was set at $P<0.05$.

\section{RESULTS}

A total of 142 subjects were screened, out of which 128 (90.1\%) were eligible and agreed to participate in the study. The mean age of all subjects was $42.67 \pm$ 12.01 years, and $82.03 \%$ were female. There were no significant differences $(P>0.05)$ between groups in age $(\mathrm{F}=0.379)$, gender $(\mathrm{F}=0.467)$, height $(\mathrm{F}=1.226)$, or weight $(\mathrm{F}=1.797)$. All demographic data for each group are shown in Table 1.

\section{Outcome measurements}

The ANOVA results revealed a significant effect for the group factor [NDI $(\mathrm{F}=278.198 ; P<0.001)$; VAS ( $\mathrm{F}=$ 24.61; $P<0.001)$; TSK-11 (F = 17.55; $P<0.001)$; Pain Du- 
TABLE 1. DEMOGRAPHIC CHARACTERISTICS OF THE NDI GROUPS. VALUES ARE MEAN \pm SD AND N (\%).

\begin{tabular}{|c|c|c|c|c|c|}
\hline & $\begin{array}{l}\text { No disability } \\
(n=32)\end{array}$ & Mild $(n=32)$ & Moderate $(n=32)$ & Severe $(n=32)$ & $\begin{array}{l}\text { P value of inde- } \\
\text { pendent samples } \\
\text { ANOVA or } c 2 \text { test }\end{array}$ \\
\hline Age (years) & $43.38 \pm 10.66$ & $40.88 \pm 11,31$ & $44 \pm 14.64$ & $42.66 \pm 11.9$ & $0.768^{*}$ \\
\hline Gender, n female (\%) & $25(78.1)$ & $25(78.1)$ & $28(87.5)$ & $27(84.4)$ & $0.698 \dagger$ \\
\hline Height (m) & $1.65 \pm 0.05$ & $1.62 \pm 0.08$ & $1.63 \pm 0.07$ & $1.65 \pm 0.07$ & $0.303^{*}$ \\
\hline Weight (kg) & $64.13 \pm 7.43$ & $61.81 \pm 12.27$ & $67.75 \pm 11.97$ & $65.5 \pm 9.58$ & $0.151^{*}$ \\
\hline NDI & N/A & $10.19 \pm 2.89$ & $18.06 \pm 2.42$ & $29.22 \pm 4.16$ & $<0.001^{\star}$ \\
\hline
\end{tabular}

Abbreviations: ANOVA, analysis of variance; N/A, not applicable; NDI, Neck Disability Index; SD, standard deviation. * ANOVA with independent samples was applied. $\dagger \mathrm{c} 2$ test was applied.

TABLE 2. COMPARISONS BETWEEN GROUPS.

\begin{tabular}{l|l|l|l|l|l|l}
\multicolumn{2}{|l|}{ Mean \pm SD } & \multicolumn{2}{l}{ Mean difference (95\% CI); } \\
& Mild & Moderate & Severe & No Disability & $\begin{array}{l}\text { a) Mild vs. Moderate } \\
\text { b) Mild vs. Severe } \\
\text { d) Moderate vs. Severe }\end{array}$ & $\begin{array}{l}\text { c) Mild vs. No Disability } \\
\text { e) Moderate vs. No Disability } \\
\text { f) Severe vs. No Disability }\end{array}$ \\
\hline $\begin{array}{l}\text { VAS } \\
(\mathrm{mm})\end{array}$ & $50 \pm 10.24$ & $53.78 \pm 10.7$ & $69.34 \pm 13.79$ & $0 \pm 0$ & $\begin{array}{l}\text { a) }-0.37(-1.05 \text { to } 0.3) \\
\text { b) }-1.93(-2.61 \text { to }-1.25) \dagger\end{array}$ & $\begin{array}{l}\text { d) } N / A \\
\text { e) } N / A \\
\text { c) }-1.55(-2.23 \text { to }-0.87) \dagger\end{array}$ \\
\hline $\begin{array}{l}\text { Pain Duration } \\
\text { (months) }\end{array}$ & $72.53 \pm 54.4$ & $\begin{array}{l}64.53 \pm \\
48.54\end{array}$ & $\begin{array}{l}211.41 \pm \\
152.74\end{array}$ & $0 \pm 0$ & $\begin{array}{l}\text { a) } 8(-48.73 \text { to } 64.73) \\
\text { b) }-138.87(-195.61 \text { to }-82.14) \dagger \\
\text { c) }-146.87(-203.61 \text { to }-90.14) \dagger\end{array}$ & $\begin{array}{l}\text { d) } N / A \\
\text { e) N/A } \\
\text { f) N/A }\end{array}$
\end{tabular}

\begin{tabular}{l|l|l|l|l|l|l}
\hline $\begin{array}{l}\text { TSK-11 } \\
(11-44)\end{array}$ & $25.25 \pm 7.03$ & $29.59 \pm 5.52$ & $28.72 \pm 9$ & $18.56 \pm 4.8$ & a) $-4.34(-8.85$ to 0.16$)$ & d) $6.68(2.18$ to 11.20$) \dagger$ \\
& & & & $\begin{array}{l}\text { b) }-3.47(-8.1 \text { to } 1.15) \\
\text { c) } 0.87(-3.75 \text { to } 5.49)\end{array}$ & $\begin{array}{l}\text { e) } 11.03(6.52 \text { to } 15.54) \dagger \\
\text { f) } 10.16(5.54 \text { to } 14.78) \dagger\end{array}$
\end{tabular}

\begin{tabular}{|c|c|c|c|c|c|c|}
\hline $\begin{array}{l}\text { Trapezius- PPT } \\
(\mathrm{kg} / \mathrm{cm} 2)\end{array}$ & $2.74 \pm 0.93$ & $2.21 \pm 0.59$ & $1.37 \pm 0.84$ & $3.79 \pm 0.84$ & $\begin{array}{l}\text { a) } 0.52 \text { (-0.1 to } 1.15) \\
\text { b) } 1.36(0.68 \text { to } 2.05) \dagger \\
\text { c) } 0.84(0.16 \text { to } 1.52) \dagger\end{array}$ & $\begin{array}{l}\text { d) }-1.04(-1.67 \text { to }-0.41) \dagger \\
\text { e) }-1.57(-2.2 \text { to }-0.94) \dagger \\
\text { f) }-2.41(-3.09 \text { to }-1.73) \dagger\end{array}$ \\
\hline $\begin{array}{l}\text { Tibialis- PPT } \\
(\mathrm{kg} / \mathrm{cm} 2)\end{array}$ & $5.61 \pm 1.83$ & $4.75 \pm 1.46$ & $3.46 \pm 1.59$ & $5.79 \pm 1.84$ & $\begin{array}{l}\text { a) } 0.85 \text { (-0.28 to } 2) \\
\text { b) } 2.15 \text { (0.8 to } 3.5) \dagger \\
\text { c) } 1.29(-0.05 \text { to } 2.64)\end{array}$ & $\begin{array}{l}\text { d) }-0.17(-1.32 \text { to } 0.96) \\
\text { e) }-1.03(-2.18 \text { to } 0.11) \\
\text { f) }-2.32(-3.67 \text { to }-0.97) \dagger\end{array}$ \\
\hline Flexion & $\begin{array}{l}52.34 \pm \\
8.63\end{array}$ & $49.06 \pm 11.48$ & $\begin{array}{l}38.89 \pm \\
13.94\end{array}$ & $58.65 \pm 8.27$ & $\begin{array}{l}\text { a) } 3.28(-3.82 \text { to } 10.38) \\
\text { b) } 13.44(5.77 \text { to } 21.12) \dagger \\
\text { c) } 10.16(2.49 \text { to } 17.83) \dagger\end{array}$ & $\begin{array}{l}\text { d) }-6.31(-13.41 \text { to } 0.78) \\
\text { e) }-9.59(-16.69 \text { to }-2.49) \dagger \\
\text { f) }-19.76(-27.43 \text { to }-12.09) \dagger\end{array}$ \\
\hline Extension & $\begin{array}{l}60.39 \pm \\
18.47\end{array}$ & $54.03 \pm 15.46$ & $48.76 \pm 19.66$ & $72.07 \pm 9.17$ & $\begin{array}{l}\text { a) } 6.35(-4.34 \text { to } 17.06) \\
\text { b) } 11.62(0.69 \text { to } 23.18)^{\star} \\
\text { c) } 5.26(-6.29 \text { to } 16.82)\end{array}$ & $\begin{array}{l}\text { d) } 11.68(-22.38 \text { to }-0.98)^{\star} \\
\text { e) } 18.04(-28.74 \text { to }-7.34) \dagger \\
\text { f) } 23.31(-34.87 \text { to }-11.75) \dagger\end{array}$ \\
\hline $\begin{array}{l}\text { Lateral Inclina- } \\
\text { tion }\end{array}$ & $34.97 \pm 7.41$ & $33.46 \pm 7.63$ & $24.57 \pm 16.51$ & $40.42 \pm 4.76$ & $\begin{array}{l}\text { a) } 1.51(-5.25 \text { to } 8.29) \\
\text { b) } 10.4(3.63 \text { to } 17.18) \dagger \\
\text { c) } 8.89(15.66 \text { to } 2.11) \dagger\end{array}$ & $\begin{array}{l}\text { d) }-5.44(-12.21 \text { to } 1.32) \\
\text { e) } 6.96(-13.73 \text { to }-0.18)^{\star} \\
\text { f) } 15.85(-22.62 \text { to }-9.07) \dagger\end{array}$ \\
\hline Rotation & $58.17 \pm 9.79$ & $56.36 \pm 12.32$ & $39.13 \pm 26.8$ & $67.16 \pm 7.6$ & $\begin{array}{l}\text { a) } 1.81(-8.94 \text { to } 12.57) \\
\text { b) } 19.04(8.27 \text { to } 29.8) \dagger \\
\text { c) } 17.22(6.46 \text { to } 27.99) \dagger\end{array}$ & $\begin{array}{l}\text { d) } 8.98(-19.83 \text { to } 1.85) \\
\text { e) }-10.8(-21.65 \text { to }-0.04) \\
\text { f) }-28.03(-38.88 \text { to }-17.18) \dagger\end{array}$ \\
\hline
\end{tabular}

Abbreviations: Cl, confidence interval; N/A, not applicable; PPT, pressure pain threshold; SD, standard deviation; TSK, Tampa Scale of kinesiophobia; VAS, Visual Analogue Scale. ${ }^{*} \mathrm{P}<0.05 . \dagger \mathrm{P}<0.01$

ration $(\mathrm{F}=22.85 ; \mathrm{P}<0.001)$; Trapezius-PPT $(\mathrm{F}=32.65$; $\mathrm{P}<0.001)$; Tibialis-PPT $(\mathrm{F}=8.67 ; \mathrm{P}<0.001)$; Flexion $(\mathrm{F}=16.85 ; \mathrm{P}<0.001) ;$ Extension $(\mathrm{F}=11.55 ; \mathrm{P}<0.001)$; Lateral flexion's ( $\mathrm{F}=13.55 ; \mathrm{P}<0.001)$; Rotations $(\mathrm{F}=$ 16.85; $\mathrm{P}<0.001)]$. In the comparisons between groups for the VAS, the differences between the MIL-SEV $(P<$ 0.01) and MOD-SEV $(P<0.01)$ disability groups were statistically significant but not between MIL-MOD ( $P$ $>0.05)$. For the TSK, there were no statistically significant differences between these groups $(P>0.05)$.
Figure 3 shows the box-plots to illustrate the TSK-11 differences between patients with different NDI level and asymptomatic subjects. Table 2 shows the values as the mean $\pm \mathrm{SD}$ of each group and the means differences (95\% CI) between them.

\section{Correlations}

The results for Pearson's correlations coefficients among the psychological and physical measures in each disability group are shown in Table 3. A mod- 
TABLE 3. CORRELATIONS BETWEEN PSYCHOLOGICAL AND PHYSICAL MEASURES.

\begin{tabular}{|c|c|c|c|c|}
\hline & & Pain Duration & VAS & TSK-11 \\
\hline & & \multicolumn{3}{|c|}{ Mild disability (5-14 NDI score) } \\
\hline \multicolumn{5}{|l|}{ PPT } \\
\hline & Trapezius & -0.099 & -0.269 & -0.026 \\
\hline & Tibialis & -0.083 & -0.062 & -0.275 \\
\hline \multicolumn{5}{|l|}{$\mathrm{ROM}$} \\
\hline & Flexion & -0.308 & -0.138 & 0.034 \\
\hline & Extension & 0.152 & -0.012 & -0.042 \\
\hline & Lateral Flexion & -0.2 & -0.183 & -0.018 \\
\hline & Rotation & -0.19 & -0.161 & -0.18 \\
\hline & & \multicolumn{3}{|c|}{ Moderate disability (15-24 NDI score) } \\
\hline \multicolumn{5}{|l|}{ PPT } \\
\hline & Trapezius & 0.188 & 0.338 & 0.107 \\
\hline & Tibialis & 0.172 & 0.11 & -0.114 \\
\hline \multicolumn{5}{|l|}{ ROM } \\
\hline & Flexion & -0.321 & 0.323 & -0.033 \\
\hline & Extension & $-0.45^{\star *}$ & -0.121 & $-0.428^{*}$ \\
\hline & Lateral Flexion & -0.167 & 0.075 & $-0.387^{\star}$ \\
\hline & Rotation & -0.244 & 0.011 & $-0.569^{\star \star}$ \\
\hline
\end{tabular}

\begin{tabular}{|c|c|c|c|c|}
\hline & & \multicolumn{3}{|c|}{ Severe disability (25-34 NDI score) } \\
\hline \multicolumn{5}{|l|}{ PPT } \\
\hline & Trapezius & $-0.445^{\star}$ & -0.108 & -0.078 \\
\hline & Tibialis & -0.199 & -0.224 & -0.364 \\
\hline \multicolumn{5}{|l|}{ ROM } \\
\hline & Flexion & 0.015 & 0.342 & -0.040 \\
\hline & Extension & $0.432^{*}$ & -0.041 & -0.124 \\
\hline & Lateral Flexion & -0.056 & $-0.423^{*}$ & -0.099 \\
\hline & Rotation & 0.015 & $-0.424^{*}$ & -0.86 \\
\hline & & \multicolumn{3}{|c|}{$\begin{array}{l}\text { Total sample with disability (5-34 NDI } \\
\text { score) }\end{array}$} \\
\hline \multicolumn{5}{|l|}{ PPT } \\
\hline & Trapezius & $-0.425^{\star *}$ & $-0.357^{\star \star}$ & -0.161 \\
\hline & Tibialis & $-0.265^{\star}$ & $-0.281^{*}$ & $-0.385^{\star *}$ \\
\hline \multicolumn{5}{|c|}{ ROM } \\
\hline & Flexion & $-0.322^{\star \star}$ & -0.054 & -0.209 \\
\hline & Extension & 0.21 & -0.165 & $-0.386^{\star \star}$ \\
\hline & Lateral Flexion & $-0.263^{\star \star}$ & $-0.367^{\star \star}$ & -0.161 \\
\hline & Rotation & $-0.262^{\star *}$ & $-0.454^{\star *}$ & $-0.212^{*}$ \\
\hline
\end{tabular}

Abbreviations: NDI, Neck Disability Index; PPT, pressure pain threshold; ROM, range of motion; TSK, Tampa kinesiophobia Scale; VAS, Visual Analogue Scale. ${ }^{*} \mathrm{p}<0.05 ;{ }^{* *} \mathrm{p}<0.01$

erate correlation was observed between TSK and Rotation $(r=-0.569)$ in the MOD group. Considering the subjects with NDI scores between 5-34 (total sample with disability), a moderate correlation was observed between NDI and VAS ( $r=0.566)$, as well as between NDI and Trapezius-PPT $(r=-0.559)$.

\section{DISCUSSION}

This is the first study to show the differences between the psychological and physical variables according to different degrees of cervical disability using the NDI sub-classification described by Vernon $^{14,15}$ the Neck Disability Index (NDI in 1991. The number of studies on this topic proved to be very small. No studies were found on non-specific neck pain. On the other hand, the authors found a classification model for whiplash using Vernon's NDI (1996) but used another form of classification. ${ }^{33,34}$

For the VAS, differences between MIL-MOD were not statistically significant, but differences between the MIL-SEV and MOD-SEV were significant. Due to the lack of studies that use levels of disability as a means of classification, the authors compared their mean \pm SD VAS scores for the MIL-MOD disability level to those in the literature, and VAS levels were very similar. ${ }^{9,35}$ The SEV group had similar VAS levels to that of chronic whiplash patients. In the same article, MIL-MOD had different VAS scores, but this could be because the sample was comprised of recovering whiplash patients. ${ }^{36}$ Emshoff et al. ${ }^{37}$ reported that, for chronic pain, the cutoff for minimal detectable change for VAS was 11.5 - $28.5 \mathrm{~mm}$, indicating that there are clinical differences between the MILSEV and MOD-SEV disability groups, but not between the MIL-MOD groups. According to Collins et al. ${ }^{38}$, a VAS above $54 \mathrm{~mm}$ is considered severe, and over $30 \mathrm{~mm}$ moderate, indicating that the SEV group $(69.34 \mathrm{~mm})$ was different than MIL $(50 \mathrm{~mm})$ and MOD (53.78mm).

The kinesiophobia levels were higher in patients with disability in comparison to those without it, but there were no differences between groups with different levels of disability. Overall, the kinesiophobia levels were moderate, in agreement with a recent study in which the authors found a moderate $(r=$ 0.46) correlation between TSK and NDI in patients with chronic neck pain; however, they included traumatic and non-traumatic neck pain disorders. ${ }^{9}$

In our results, TSK outcomes were between $25.25 \pm 7.03$ and $29.59 \pm 7.03$ in all the patients with disability, and there were no statistically significant differences between the groups with different levels of disability. Our outcomes did not reach the kinesiophobia levels reported by Sarig Bahat et al. ${ }^{9}(35.74 \pm 5.71)$, possibly because they evaluated patients with different neck pain, such as traumatic neck pain or non-specific acute neck pain, and 
used a larger version of the TSK (17-items). Saavedra-Hernández et al. reported similar levels of kinesiophobia to our study $(25.4 \pm 6.5)$, but in patients with moderate disability. ${ }^{8}$

Regarding the PPT results, there were no statistically significant differences in the trapezius for MIL and MOD, but differences were statistically significant between the MIL-SEV and MOD-SEV groups. In addition, all groups had differences compared to the non-disabled group. For the right tibial anterior, differences were only found between the MIL-SEV and SEV-Control groups. These results are in agreement with La Touche et al. ${ }^{39}$, who compared groups with moderate disability versus no disability subjects and had very similar PPT values in the trapezius and anterior tibial muscles and conclusions similar to ours. ${ }^{39}$ Furthermore, PPT differences ranging from $123 \mathrm{kPa}$ to $200 \mathrm{kPa}(1.2-2 \mathrm{~kg})$ are considered minimal detectable change differenc$\mathrm{es}^{28,40-42}$ at two points on the trapezius muscles on each side and at the sternum as the only non-muscular site. The intratester repeatability of the PPT measurements was satisfactory or good (Intraclass correlation coefficient (ICC 0.78-0.93 Therefore, it can be suggested that, for trapezius-PPT, there are real differences between the SEV-MIL $\left(1.37 \mathrm{~kg} / \mathrm{cm}^{2}\right)$ and SEV-no disability $\left(2.42 \mathrm{~kg} / \mathrm{cm}^{2}\right)$ groups, but not between the SEV-MOD $\left(0.84 \mathrm{~kg} / \mathrm{cm}^{2}\right)$ or MOD-MIL $\left(0.53 \mathrm{~kg} / \mathrm{cm}^{2}\right)$ ones. This suggestion could be related to mechanical hyperalgesia.

In relation with ROMs, disability groups had significant differences with respect to the non-disabled group, which coincides with previous studies. .,16,26,43 $^{2}$ In addition, the SEV group has more differences from the other disability groups, especially in rotation movements. Sarig Bahat et al. ${ }^{9}$ demonstrated that decreased CROM correlates with more kinesiophobia, more pain intensity, and a higher level of disability. This could explain our results, in which a higher level of disability obtained minor ROMs. Furthermore, the relationship between kinematics and fear of motion suggests that psychological fear may affect cervical motion control., ${ }^{9,12,16,36,43} \mathrm{NDI}$ and other questionnaires, whiplash and NDI and cervical range of motion and NDI. The NDI was shown to be a well validated and reliable self-reported questionnaire, especially when compared to other questionnaires, in both neck pain and whiplash (WAD This also justifies our results, in which all disability groups presented kinesiophobia and reduced ROMs.

\section{Study limitations}

This study has several limitations. First, the complete disability group (NDI between $35-50)^{15}$ especially those involving the soft tissues, represent a significant source of chronic disability. Methods of assessment for such disability, especially those targeted at activities of daily living which are most affected by neck pain, are few in number. A modification of the Oswestry Low Back Pain Index was conducted producing a 10-item scaled questionnaire entitled the Neck Disability Index (NDI was not accounted for due to the lack of sample in clinical practice; this type of subject usually has polytrauma or accidents, and the access necessary to take certain measurements is limited. Second, because of the involvement of the psychological factor in chronic pain, we only measured kinesiophobia, but we should account for the measurement of depression, anxiety, and catastrophizing to observe if there are differences in different levels of neck disability. Third, the authors did not evaluate the reliability of the ROM and PPT measures, and this kind of clinical measure could be influenced by the skills of the rater. Another limitation is that this research was a cross-sectional study; hence, its results should be considered with caution because we do not know the outcomes of these patients over time. Thus, future studies should consider a longitudinal design and the implementation of linear regression analysis to establish a causal relationship per disability group.

\section{Interpretation}

Our findings suggest that there are differences between the different types of disability, which may have implications in both clinical practice and research. Having the NDI tool to classify disability in nonspecific neck pain will increase awareness of their differences and can be the key to selecting the best intervention for each patient. In research, nonspecific neck pain randomized controlled trials (RCT) are almost nonexistent when it comes to samples exclusively composed of severely disabled patients; most have a mild to moderate disability level.

\section{Prospective and future studies}

Future research could present different types of specific treatments for different levels of disability, but RCTs exclusive for patients with severe neck disability are needed, for they are not found in the current literature. According to this, pain education pro- 
grams combined with multimodal treatments were shown to be beneficial for patients with chronic neck pain ${ }^{44}$ nevertheless the neck disability level should be related to the clinical course and treatment effectiveness.

\section{CONCLUSIONS}

Kinesiophobia may not be influenced by disability level in patients with chronic non-specific neck pain.
Nevertheless, pain intensity and chronicity of patients with severe neck disability are increased with respect to mild and moderate disability indexes. In addition, patients with more disability showed higher local hyperalgesia, although differences in widespread hyperalgesia were only found when mild and severe disabilities were compared. Finally, the severe disability group showed more differences in ROM than the rest of the subgroups, especially in rotation movements.

\section{RESUMO}

CONTEXTO: Até a data, não há estudos transversais considerando a influência do nível de incapacidade em pacientes com dor de garganta crônica não específica. Portanto, o objetivo principal deste estudo foi determinar a diferença entre os níveis de diminuição do colesterol cervical (Crom) e o limiar por dor de pressão (PPT) entre diferentes níveis de incapacidade (leve, moderada e grave) em indivíduos com dor crônica não específica no pescoço e sujeitos assintomáticos.

MÉTODOs: Estudo descritivo transversal. Os indivíduos foram recrutados de um centro de saúde primário e de um hospital do departamento ambulatorial. Uma amostra total de 128 indivíduos, 96 indivíduos com dor no pescoço crônica não específica e 32 indivíduos assintomáticos, foi recrutada. O NDI foi usado para dividir os indivíduos com dor no pescoço crônica em três grupos (incapacidade leve, moderada e grave). A principal medida de resultados foi a Tampa Scale of Kinesiophobia (TSK-11). As medidas de resultado secundário foram a Escala Analógica Visual (VAS), PPT (trapézio e tibial anterior), Crom (flexão, extensão, rotação e inclinação lateral) e duração da dor.

RESULTADOS: Nos resultados da Anova revelados nas comparações entre os grupos, diferenças estatisticamente significativas para o VAS foram observadas entre os grupos leve-grave $(P<0,01)$ e moderado-grave $(P<0,01)$, mas não entre os grupos moderado-moderado $(P>0,05)$. Para o TSK, as diferenças não foram estatisticamente significativas $(P>0,05)$.

CONCLUSÃO: A cinesiofobia pode não ser influenciada pelo nível de incapacidade em pacientes com dor no pescoço crônica não específica. No entanto, a intensidade da dor e a cronicidade de pacientes com deficiência grave do pescoço são aumentadas em relação ao índice de incapacidade leve e moderada.

PALAVRAS-CHAVE: Cervicalgia. Dor crônica. Avaliação da deficiência.

ABREVIAÇÕES: Faixa de movimento cervical (Crom); Índice de incapacidade do pescoço (NDI); Limiar da dor de pressão (PPT); Tampa Scale of Kinesiophobia (TSK-11); Escala Visual Analógica (VAS).

\section{REFERENCES}

1. Haldeman S, Carroll L, Cassidy JD. Findings from the bone and joint decade 2000 to 2010 task force on neck pain and its associated disorders. Occup Environ Med. 2010;52(4):424-7.

2. Carroll LJ, Hogg-Johnson S, van der Velde G, Haldeman S, Holm LW, Carragee El, et al. Course and prognostic factors for neck pain in the general population: results of the Bone and Joint Decade 2000-2010 Task Force on Neck Pain and Its Associated Disorders. J Manipulative Physiol Ther. 2009;32(2 Suppl):S87-96.

3. Hogg-Johnson S, van der Velde G, Carroll LJ, Holm LW, Cassidy JD, Guzman J, et al. The burden and determinants of neck pain in the general population: results of the Bone and Joint Decade 2000-2010 Task Force on Neck Pain and Its Associated Disorders. I Manipulative Physiol Ther. 2009;32(2 Suppl):S46-60.

4. Fejer R, Kyvik KO, Hartvigsen J. The prevalence of neck pain in the world population: a systematic critical review of the literature. Eur Spine J. 2006;15(6):834-48.

5. Hoy D, March L, Woolf A, Blyth F, Brooks P, Smith E, et al. The global burden of neck pain: estimates from the global burden of disease 2010 study. Ann Rheum Dis. 2014;73(7):1309-15.

6. Binder Al. Neck pain. BMJ Clin Evid. 2008;2008. pii: 1103.

7. Bogduk N. Neck pain. Aust Fam Physician. 1984;13(1):26-30

8. Saavedra-Hernández $M$, Castro-Sánchez AM, Cuesta-Vargas Al, Cleland IA, Fernández-de-las-Peñas C, Arroyo-Morales M. The contribution of previous episodes of pain, pain intensity, physical impairment, and pain-related fear to disability in patients with chronic mechanical neck pain. Am J Phys Med Rehabil. 2012;91(12):1070-6.

9. Sarig Bahat H, Weiss PL, Sprecher E, Krasovsky A, Laufer Y. Do neck kinematics correlate with pain intensity, neck disability or with fear of motion? Man Ther. 2014;19(3):252-8.

10. Hudes K. The Tampa Scale of Kinesiophobia and neck pain, disability and range of motion: a narrative review of the literature. J Can Chiropr Assoc. 2011;55(3):222-32.

11. Vlaeyen JW, Linton SJ. Fear-avoidance and its consequences in chronic musculoskeletal pain: a state of the art. Pain. 2000;85(3):317-32

12. Leeuw M, Goossens ME, Linton SJ, Crombez G, Boersma K, Vlaeyen JW. The fear-avoidance model of musculoskeletal pain: current state of scientific evidence. J Behav Med. 2007;30(1):77-94.

13. Sá S, Silva AG. Repositioning error, pressure pain threshold, catastrophizing and anxiety in adolescents with chronic idiopathic neck pain. Musculoskelet Sci Pract. 2017;30:18-24.

14. Vernon H. The Neck Disability Index: state-of-the-art, 1991-2008. J Manipulative Physiol Ther. 2008;31(7):491-502.

15. Vernon $H$, Mior S. The Neck Disability Index: a study of reliability and validity. J Manipulative Physiol Ther. 1991;14(7):409-15.

16. Howell ER. The association between neck pain, the Neck Disability Index and cervical ranges of motion: a narrative review. J Can Chiropr Assoc. 2011;55(3):211-21. 
17. MacDermid JC, Walton DM, Avery S, Blanchard A, Etruw E, McAlpine C, et al. Measurement properties of the neck disability index: a systematic review. J Orthop Sports Phys Ther. 2009;39(5):400-17.

18. Borghouts JA, Koes BW, Bouter LM. The clinical course and prognostic factors of non-specific neck pain: a systematic review. Pain. 1998;77(1):113.

19. von Elm E, Altman DG, Egger M, Pocock SI, Gøtzsche PC, Vandenbroucke IP; Iniciativa STROBE. The Strengthening the Reporting of Observational Studies in Epidemiology (STROBE) statement: guidelines for reporting observational studies. Rev Esp Salud Publica. 2008;82(3):251-9.

20. Andrade Ortega JA, Delgado Martínez AD, Almécija Ruiz R. Validation of the Spanish version of the Neck Disability Index. Spine (Phila Pa 1976). 2010;35(4):E114-8.

21. Wolfe F, Clauw DJ, Fitzcharles MA, Goldenberg DL, Katz RS, Mease P, et al. The American College of Rheumatology preliminary diagnostic criteria for fibromyalgia and measurement of symptom severity. Arthritis Care Res (Hoboken). 2010;62(5):600-10.

22. Jensen MP, Turner JA, Romano JM, Fisher LD. Comparative reliability and validity of chronic pain intensity measures. Pain. 1999;83(2):157-62.

23. Katz J, Melzack R. Measurement of pain. Surg Clin North Am. 1999;79(2):231-52

24. Gómez-Pérez L, López-Martínez AE, Ruiz-Párraga GT. Psychometric properties of the Spanish version of the Tampa Scale for Kinesiophobia (TSK). J Pain. 2011;12(4):425-35.

25. Roelofs J, Goubert L, Peters ML, Vlaeyen JW, Crombez G. The Tampa Scale for Kinesiophobia: further examination of psychometric properties in patients with chronic low back pain and fibromyalgia. Eur | Pain. 2004;8(5):495-502.

26. Fletcher JP, Bandy WD. Intrarater reliability of CROM measurement of cervical spine active range of motion in persons with and without neck pain. J Orthop Sports Phys Ther. 2008;38(10):640-5.

27. Fischer AA. Pressure algometry over normal muscles. Standard values, validity and reproducibility of pressure threshold. Pain. 1987;30(1):115-26.

28. Chesterton LS, Sim J, Wright CC, Foster NE. Interrater reliability of algometry in measuring pressure pain thresholds in healthy humans, using multiple raters. Clin J Pain. 2007;23(9):760-6.

29. Faul F, Erdfelder E, Lang AG, Buchner A. G*Power 3: a flexible statistical power analysis program for the social, behavioral, and biomedical sciences. Behav Res Methods. 2007;39(2):175-91.

30. Nixon RM, Wonderling D, Grieve RD. Non-parametric methods for cost-effectiveness analysis: the central limit theorem and the bootstrap compared. Health Econ. 2010;19(3):316-33.
31. Mouri H. Log-normal distribution from a process that is not multiplicative but is additive. Phys Rev E Stat Nonlin Soft Matter Phys. 2013;88(4):042124.

32. Mukaka MM. Statistics corner: a guide to appropriate use of correlation coefficient in medical research. Malawi Med J.2012;24(3):69-71.

33. Sterling M, Jull G, Vicenzino B, Kenardy ], Darnell R. Physical and psychological factors predict outcome following whiplash injury. Pain. 2005;114(12):141-8.

34. Vernon $\mathrm{H}$. The neck disability index: patient assessment and outcome monitoring in whiplash. J Musculoskelatal Pain. 1996;4(4).

35. Leaver AM, Maher CG, McAuley JH, Jull GA, Refshauge KM. Characteristics of a new episode of neck pain. Man Ther. 2013;18(3):254-7.

36. Nederhand MI, lizerman MI, Hermens HI, Turk DC, Zilvold G. Predictive value of fear avoidance in developing chronic neck pain disability: consequences for clinical decision making. Arch Phys Med Rehabil. 2004;85(3):496-501.

37. Emshoff R, Bertram S, Emshoff I. Clinically important difference thresholds of the visual analog scale: a conceptual model for identifying meaningful intraindividual changes for pain intensity. Pain. 2011;152(10):2277-82.

38. Collins SL, Moore RA, McQuay HJ. The visual analogue pain intensity scale: what is moderate pain in millimetres? Pain. 1997;72(1-2):95-7.

39. La Touche R, Fernández-de-Las-Peñas C, Fernández-Carnero |, Díaz-Parreño S, Paris-Alemany A, Arendt-Nielsen L. Bilateral mechanical-pain sensitivity over the trigeminal region in patients with chronic mechanical neck pain. J Pain. 2010;11(3):256-63.

40. Ylinen J, Nykänen M, Kautiainen $\mathrm{H}$, Häkkinen A. Evaluation of repeatability of pressure algometry on the neck muscles for clinical use. Man Ther. 2007;12(2):192-7.

41. Sterling M, Jull G, Carlsson Y, Crommert L. Are cervical physical outcome measures influenced by the presence of symptomatology? Physiother Res Int. 2002;7(3):113-21.

42. Walton DM, Macdermid IC, Nielson W, Teasell RW, Chiasson M, Brown L. Reliability, standard error, and minimum detectable change of clinical pressure pain threshold testing in people with and without acute neck pain. J Orthop Sports Phys Ther. 2011;41(9):644-50.

43. Howell ER, Hudes K, Vernon H, Soave D. Relationships between cervical range of motion, self-rated disability and fear of movement beliefs in chronic neck pain patients. J Musculoskelet Pain. 2012;20(1):18-24.

44. Beltran-Alacreu H, López-de-Uralde-Villanueva I, Fernández-Carnero I, La Touche R. Manual therapy, therapeutic patient education, and therapeutic exercise, an effective multimodal treatment of nonspecific chronic neck pain: a randomized controlled trial. Am J Phys Med Rehabil. 2015;94(10 Suppl 1):887-97. 
Erratum

http://dx.doi.org/10.1590/1806-9282.65.2.291

Regarding the article "Clinical features of patients with chronic non-specific neck pain per disability level: A novel observational study", with DOI number: http://dx.doi.org/10.1590/1806-9282.64.08.700, published in Journal of the Brazilian Medical Association, 2018;64;08, page 700:

Where was written: "Roy La Touche, PT, PhD"1,2,34"

Now Read: "Roy LA TOUCHE, PT, PhD 1,2,3,4" 